\title{
Local Economic Base, Geographic Diversification, and Risk Management of Mortgage Portfolios
}

\author{
John B. Corgel* and Gerald D. Gay**
}

\begin{abstract}
Variability of local economic conditions underlie, in part, the default and prepayment risks of mortgages originated in a metropolitan area. In this study we examine the benefits of diversifying across metropolitan areas for reducing these risks. Employment data for the thirty largest metropolitan areas in the United States, divided into eight industry groups, are analyzed with the aid of factor and principal component analysis to determine if the variances of employment changes across the thirty areas are independent. Independence is investigated to assess the potential for diversification. Mean-variance portfolio analysis is then used to measure the gains from geographic diversification vis-à-vis a set of several alternative strategies for diversification. We conclude that geographic diversification is an important mortgage portfolio objective and that meanvariance strategies outperform the alternative strategies tested here.
\end{abstract}

\section{INTRODUCTION}

Recent studies of mortgage default by Vandell and Thibodeau [18] and mortgage prepayment by Green and Shoven [8] indicate that these mortgage risks are largely systematic. Deteriorating economic conditions (i.e., rising unemployment and reduced consumer demand) lower the values of properties relative to their outstanding mortgage debt and thus raise mortgage default rates. Declining interest rates lower market coupon rates relative to cournns on outstanding mortgage debt

\footnotetext{
* Department of Real Estate, Georgia State University, Atlanta, Georgia 30303.

** Department of Finance, Georgia State University.

Date Received: December 1985; Revised: February 1987.
} 
and thus raise the level of mortgage prepayment. These findings are consistent with earlier work on defaults and prepayments (see, for example, Sandor and Sosin [15] and Vandell [17], and Peters, Pinkus and Askin [14]) and generally support the use of option pricing models to value default and prepayment options in mortgage contracts (see, for example, Epperson, Kau, Keenan and Muller [5], Hall [9], and Dunn and McConnell $[3,4]$.

While systematic factors are central to the mortgagor's decision to prepay or default, unsystematic factors are also important in understanding mortgage default (Foster and Van Order [6]) and the pricing of mortgage insurance (Cunningham and Hendershott [2]). These factors relate to specific characteristics of the mortgage, the borrower, the property, the neighborhood, and the local economic environment. Specifically, Vandell and Thibodeau [18] find that default experience is highly dependent on the expected loan-to-value ratio. Yet, if such characteristics are unsystematic, they will be inconsequential to the diversified investor.

In this study, we are concerned with the importance of diversifying according to the local economic environment. Campbell and Dietrich [1] find that recent residential mortgage "default experience has been significantly influenced by changes in regional rates of unemployment" (p.158). Moreover, the simple correlation of aggregate mortgage loan delinquencies with aggregate employment growth is near zero. Thus, geographic diversification as Campbell and Dietrich suggest, may be an important consideration for the management of default risk in mortgage portfolios.

Monthly rates of change in employment levels among industry groups in the thirty largest United States metropolitan areas are selected to measure local economic growth (decline) and stability. In the first phase of the study, factor and principal-component analysis are used to determine if the variance of employment changes across industries and across local economies are independent. To the extent that nonsystematic factors are present in the variances, and that these contribute to similar nonsystematic factors in mortgage default rates, suggests that diversification across geographic areas may be beneficial.

The second phase of the study involves an application of portfolio theory to measure the gains from diversification across metropolitan areas. This is accomplished by first dividing the data into two time periods. Data from the first time period are used to construct an efficient frontier of portfolio holdings. Portfolio weights from points along this efficient frontier are used to construct portfolios for investment in the second time period. The risk and return characteristics of these portfolios are compared with those of eleven ad hoc investment strategies, 
including an equal amount strategy, a sunbelt strategy, large and small metropolitan area strategies, a maximum return strategy, a minimum variance strategy, and strategies based on the degree of concentration of industry employment. In each instance the ex ante efficient portfolios dominate the alternative strategies.

The balance of the paper is organized as follows. Descriptions of the data and the methodology are presented in the second section along with the results from the factor analysis. Section three compares the benefits from mean-variance diversification strategies vis-à-vis a set of alternative diversification strategies. A summary of the results of the study is provided in the final section.

\section{POTENTIAL GAINS FROM DIVERSIFICATION}

The potential for risk reduction through geographic diversification at the metropolitan area level is examined with the use of data on monthly employment for the thirty largest standard metropolitan areas (SMAs) in the United States as of the 1980 U.S. Census of the Population. The thirty SMAs are presented in Table 1-A. The employment data include total area employment as well as employment totals for each of the eight designated industry groups listed in Table 1-B. The data span the time period January 1969 through September 1984 and are taken from various issues of Employment and Earnings, published by the U.S. Bureau of Labor Statistics. Monthly rates of change in employment are computed as the natural logarithm of successive industry employment totals. This produces a total of $N=188$ observations for each SMA industry component. ${ }^{1}$

The covariances of the rates of change in total SMA employment can be used directly to examine whether the variances are independent of one another. This approach, however, is unlikely to expose complex relationships that may exist among industry groups of these metropolitan economies. For this reason, multivariate methods of factor and principal-component analysis are used..$^{2} \mathrm{~A}$ vector of observations (i.e., the monthly industry growth rates for each metropolitan area) is the input to the principal component model. It is possible to express a set

\footnotetext{
${ }^{1}$ In addition to the above employment figures, we gathered monthly data on rates of mortgage loan delinquencies for the United States over 1973-1984 period as reported by the Federal Home Loan Bank Board. The correlation between these figures and the monthly rates of United States employment growth produced a high negative correlation coefficient of -.48 , which provides additional support to the notion that the strength of the economic base of a metropolitan area is strongly related to its mortgage default experience.

${ }^{2}$ For a thorough discussion of factor and principal-component analysis see Mardia, Kent and Bibby [13]. This form of analysis has been applied previously, for example, to common stock returns by King [11] and Lessard [12].
} 


\title{
TABLE 1-A
}

\section{Standard Metropolitan Areas Used in Analysis (30 Largest as of 1980 Census) ${ }^{a}$}
1. Phoenix
2. Los Angeles
3. San Diego
4. San Francisco
5. Denver
6. Washington, D.C.
7. Miami
8. Tampa
9. Atlanta
10. Chicago
11. Indianapolis
12. New Orleans
13. Baltimore
14. Boston
15. Detroit
16. Minneapolis
17. Kansas City
18. St. Louis
19. Buffalo
20. New York City
21. Cincinnati
22. Cleveland
23. Columbus
24. Portland (OR)
25. Philadelphia
26. Pittsburgh
27. Dallas
28. Houston
29. Seattle
30. Milwaukee

a SMAs are listed alphabetically by the state within which each is located.

\section{TABLE 1-B}

\section{Industry Components of Total Employment}

\author{
1. Mining \\ 2. Construction \\ 3. Manufacturing \\ 4. Transportation and Public Utilities \\ 5. Wholesale and Retail Trade \\ 6. Finance, Insurance, and Real Estate \\ 7. Services \\ 8. Government
}

of industry observations as a function of several underlying factors and a unique element. These factors may be common to each industry within a given SMA in terms of contributing to their variance or may be common to only a specific subset of them. Factors are selected such that the first principal component explains the largest amount of variance, the second principal component explains most of the remaining variance, and so on.

Principal-component analysis is applied to the variance-covariance matrix of industry rates of change for each of the thirty SMAs. The cumulative proportions of total viariance explained by the first and second principal components are reported in Table 2 . The results indicate that, on average, the first component explains over $33 \%$ of variation in 
TABLE 2

\section{Cumulative Proportions of Variance Explained By First Two Principal Components}

SMA
Phoenix
Los Angeles
San Diego
San Francisco
Denver
Washington, D.C.
Miami
Tampa
Atlanta
Chicago
Indianapolis
New Orleans
Baltimore
Boston
Detroit
Minneapolis
Kansas City
St. Louis
Buffalo
New York City
Cincinnati
Cleveland
Columbus
Portland
Philadelphia
Pittsburgh
Dallas
Houston
Seattle
Milwaukee

\begin{tabular}{|c|c|}
\hline First & $\begin{array}{l}\text { First and } \\
\text { Second }\end{array}$ \\
\hline 42.8 & 59.1 \\
\hline 30.8 & 48.3 \\
\hline 25.4 & 42.6 \\
\hline 31.1 & 49.0 \\
\hline 44.6 & 60.9 \\
\hline 35.6 & 50.7 \\
\hline 31.1 & 51.0 \\
\hline 45.7 & 60.7 \\
\hline 33.4 & 48.8 \\
\hline 27.2 & 49.7 \\
\hline 32.2 & 51.8 \\
\hline 23.5 & 43.7 \\
\hline 36.5 & 56.4 \\
\hline 31.4 & 48.5 \\
\hline 35.4 & 55.9 \\
\hline 32.5 & 51.7 \\
\hline 29.3 & 47.1 \\
\hline 27.2 & 44.5 \\
\hline 34.0 & 50.3 \\
\hline 36.0 & 54.8 \\
\hline 39.3 & 56.1 \\
\hline 37.8 & 53.5 \\
\hline 38.6 & 57.1 \\
\hline 36.8 & 57.1 \\
\hline 30.3 & 48.2 \\
\hline 27.1 & 44.4 \\
\hline 25.8 & 43.5 \\
\hline 32.4 & 52.3 \\
\hline 42.1 & 59.3 \\
\hline 31.1 & 49.5 \\
\hline
\end{tabular}

local employment with the second component explaining an additional $18 \%$. Given the sizable amount of explanatory power of the first principal components, there appears to be a locally strong economic force in each area that affects employment across all industries in the area.

A more important question for addressing the potential gains from geographic diversification is how closely are these local market forces or movements related. Table 3 presents a summary of the correlations of the first principal-component scores for the thirty SMAs. ${ }^{3}$ Over $46 \%$ of the correlation coefficients are positive and significant; however, the results are not consistently significant for any of the SMAs, as many insignificant and negative values are observed. The results from the multivariate analysis indicate that each local economy is heavily influ-

${ }^{3}$ The full correlation matrix is available from the authors upon request. 


\section{TABLE 3}

\section{Correlation Summary of First}

Principal Component Scores ${ }^{\mathrm{a}, \mathrm{b}}$

\begin{tabular}{|c|c|c|}
\hline Correlation Range & Number & $\begin{array}{l}\text { Cumulative } \\
\text { Percentage }\end{array}$ \\
\hline $.8-1.0$ & 0 & 0 \\
\hline $.6-.799$ & 27 & 6.2 \\
\hline $.4-.599$ & 49 & 17.5 \\
\hline $.2-.399$ & 83 & 36.6 \\
\hline $.143^{a}-.199$ & 42 & 46.2 \\
\hline $0-.142$ & 134 & 77.0 \\
\hline$-.2-.001$ & 72 & 93.5 \\
\hline$-.4--.201$ & 19 & 97.9 \\
\hline$\leq-.401$ & 9 & 100.0 \\
\hline & 435 & \\
\hline
\end{tabular}

\footnotetext{
${ }^{\mathrm{a}}$ For $n=188, r=.143$ is significant at .05 level (two-tailed test).

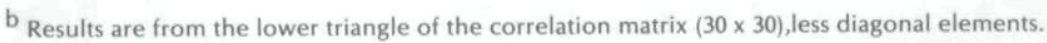

enced by a dominant economic factor. Yet, when these factors are compared across local economies, there are significant differences suggesting that the benefits from geographic diversification may be substantial.

\section{BENEFITS FROM GEOGRAPHIC DIVERSIFICATION}

In this section we measure the magnitude of the gains from geographic diversification; the performance of two different types of ex ante diversification strategies are compared. The first type corresponds to mean-variance efficiency, while the second type is represented by a series of ad hoc diversification strategies. To begin, the data are divided into two equal time periods each with ninety-four months of data. Using monthly rates of change in total employment for each SMA from the first time period, an efficient frontier, reflecting optimal diversification, is formed. This set of portfolios reflects all combinations of SMAs having minimum variance for given rates of 
employment change. ${ }^{4}$ For illustration, the investment proportions for one of the selected portfolios, the minimum-variance portfolio, are shown in Table 4 . It is interesting to note that more than $50 \%$ of this portfolio is concentrated in the SMAs of Dallas and Houston and that all but approximately $20 \%$ of the portfolio is concentrated in sunbelt SMAs. ${ }^{5}$ From the ex ante efficient frontier, ten portfolios are arbitrarily selected (including the minimum variance and maximum return portfolios). These ten portfolios are denoted as EF1-10. Using data from the second half of the time period, the ex post performance results of these ten portfolios is computed. These results are reported later in Table 6.

The efficient frontier strategy described above is a feasible and easily implementable strategy for portfolio managers. Several alternative strategies, labeled the "naive" strategies, are devised and tested. The first of these strategies, $(N 1)$, a "large city" strategy, involves equal proportions in the ten largest SMAs (according to 1980 population). These ten SMAs are listed in the first row of Table 5. The second naive strategy, (N2), involves equal proportions in the ten SMAs with the smallest population totals. We refer to strategy $N 3$ as a "sunbelt" strategy. It represents an equal proportion in the nine SMAs located in the southwest and southeast regions of the United States. Strategy N4 involves equal proportions in the ten SMAs having the greatest rate of change in employment during the first half of the study period; strategy N5 represents an equal allocation in the ten SMAs having highest variance; and strategy $N 6$ represents an equal allocation in the ten SMAs having the lowest variance during the first half of the time period. Strategy $N 7$ represents an equal proportion in all thirty SMAs (a $1 / N$ strategy).

The remaining four naive strategies are based on concentration measures of employment. Measures of concentration are useful for analyzing the industry structure of an area in terms of its dependence on a particular industry category (e.g., manufacturing). Presumably, default and prepayment risk would be greater in areas in which the economic base is heavily concentrated in one or two industries. Two alternative measures of concentration are used. The first is the GibbsMartin [7] index of diversification, which is calculated according to $1-\Sigma X_{\mathrm{Z}} /(\Sigma X)_{2}$, where $X$ is the number of employees in each industry category of a particular SMA. If the labor force is wholly concentrated in a single industry, the index is zero; if it is evenly distributed the index is one. The Gibbs-Martin index of concentration is calculated for

\footnotetext{
${ }^{4}$ The efficient frontier was determined with the additional restriction of nonnegative investment proportions, which is analogous to a short-selling constraint.

${ }^{5}$ These results are for the period 1/69 through 10/76.
} 


\section{TABLE 4}

\section{Composition of the Ex-Ante} Minimum-Variance Portfolio: 1/69 - 10/76

SMA

(3) San Diego

(6) Washington, D.C.

(7) Miami

(8) Tampa

(10) Chicago

(12) New Orleans

(20) New York

(27) Dallas

(28) Houston

Total
Percent

Investment

0.7

3.0

13.2

2.0

8.9

5.9

9.9

28.1

28.3

100.0

TABLE 5

\section{Summary of Various Naive Strategy Compositions ${ }^{a}$}

\begin{tabular}{|c|c|c|}
\hline & Name & SMAs Included \\
\hline N1 & Large City & $(2),(4),(6),(10),(14),(15),(20),(25),(27),(28)$ \\
\hline N2 & Small City & $(1),(5),(8),(11),(12),(17),(19),(23),(24),(30)$ \\
\hline N3 & Sunbelt & $(1),(2),(3),(7),(8),(9),(12),(27),(28)$ \\
\hline N4 & High Return & $(1),(3),(5),(6),(8),(9),(23),(24),(27),(28)$ \\
\hline N5 & High Variance & $(1),(3),(5),(7),(8),(9),(15),(16),(19),(23)$ \\
\hline N6 & Low Variance & $(2),(4),(10),(11),(12),(14),(20),(26),(27),(28)$ \\
\hline N7 & Equal Weight & equal investment in all 30 SMAs \\
\hline N8 & High Concentration I & $(2),(3),(6),(10),(14),(15),(19),(21),(22),(30)$ \\
\hline N9 & High Concentration II & $(2),(3),(6),(10),(14),(15),(19),(21),(22),(30)$ \\
\hline N10 & Low Concentration I & $(4),(5),(7),(12),(13),(17),(20),(24),(28),(29)$ \\
\hline V11 & 1 Low Concentration II & $(4),(5),(7),(9),(12),(13),(20),(24),(28),(29)$ \\
\hline
\end{tabular}

a See Table 1-A for a list of SMAs and their corresponding identification numbers. 
each of the thirty SMAs. The ten SMAs having the lowest index numbers (high concentration), are combined for strategy $N 8$, while those then having the highest index numbers (low concentration) are combined for strategy N10.

A second measure often used for measuring employment concentration is based on the Lorenz curve. ${ }^{6}$ An index of concentration can be calculated from a Lorenz curve according to

$$
\left.\underset{\substack{i=1 \\
\sum}}{i} \quad \begin{array}{c}
i \\
j=1
\end{array} S_{j}\right),
$$

where $S_{j}$ is the percentage of total employment represented by industry $j$ and where the industries are first ranked from high to low in terms of employment. The higher the value of this index the greater the concentration in one industry. Strategy N9 represents an equal investment in the ten SMAs having the highest concentration according to this measure, while strategy $N 11$ corresponds to an investment in the ten areas having lowest concentration.

The ex post performance of each of the eleven naive strategies is presented in Table 6 along with the performance of the ten selected portfolios from the ex post efficient frontier. Generally, the portfolios on the efficient frontier dominate the eleven naive portfolio strategies examined in this study. With the exception of the ex ante maximumreturn portfolio (a nondiversified portfolio), the $E F$ portfolios have consistently higher rates of change in employment for given levels of variance as compared with the naive strategies. These results suggest that a mean-variance approach to geographic diversification is superior to ad hoc diversification schemes.

Figure 1 displays the findings in Table 5 graphically. ${ }^{7}$ The line connecting points $E F^{*} 1$ through $E F^{*} 10$ is an efficient frontier computed with data from the second half of the sample period (11/76-9/84). These results occur with perfect investor foresight, and are included simply for visual comparison.

\section{SUMMARY}

Changes in local economic conditions have been shown previously to be important for explaining mortgage defaults and prepayment. If these changes have unsystematic components, then geographic diversi-

\footnotetext{
${ }^{6}$ For further information regarding the Lorenz curve, see Hammond and McCullagh [10].

${ }^{7}$ Note that the numbers in Table 6 are expressed as annual rates of change, while in Figure 1, they are graphed as monthly (times 100) rates.
} 
TABLE 6

\section{Summary of Ex-Post Investment Performance (Numbers are annual rates)}

\begin{tabular}{|c|c|c|c|}
\hline & & Mean & $\begin{array}{l}\text { Standard } \\
\text { Deviation }\end{array}$ \\
\hline \multicolumn{4}{|l|}{ I. Efficient Frontier Strategies } \\
\hline & EF1 & .0340 & .0176 \\
\hline & EF2 & .0360 & .0142 \\
\hline & EF3 & .0382 & .0180 \\
\hline & EF4 & .0397 & .0183 \\
\hline & EF5 & .0410 & .0189 \\
\hline & EF6 & .0428 & .0206 \\
\hline & EF7 & .0439 & .0216 \\
\hline & EF8 & .0445 & .0228 \\
\hline & EF9 & .0450 & .0266 \\
\hline & EF10 & .0410 & .0322 \\
\hline \multicolumn{4}{|l|}{ II. Naive Strategies } \\
\hline & N1 & .0202 & .0233 \\
\hline & N2 & .0242 & .0256 \\
\hline & N3 & .0413 & .0230 \\
\hline & N4 & .0408 & .0228 \\
\hline & N5 & .0322 & .0270 \\
\hline & N6 & .0196 & .0223 \\
\hline & N7 & .0221 & .0240 \\
\hline & N8 & .0120 & .0237 \\
\hline & N9 & .0120 & .0237 \\
\hline & N10 & .0247 & .0224 \\
\hline & N11 & .0282 & .0217 \\
\hline
\end{tabular}

fication is likely to be beneficial to holders of mortgage portfolios. Moreover, naive diversification strategies customarily used, may be suboptimal to mean-variance-based portfolio strategies.

In this study we examine the potential for geographic diversification and compare various alternative diversification strategies. Using monthly rates of change in employment levels for the thirty largest United States metropolitan areas over the period 1969 through 1984, we find that factors underlying employment changes (as a proxy for local economic conditions) are largely unsystematic. Further, we show that a diversification strategy based on mean-variance efficiency is superior to the various ad hoc strategies we tested.

Holders of mortgage portfolios know instinctively that their mortgage investment activities should not be constrained to one or perhaps a few local areas. They realize that gains, in terms of risk reduction, are achieved through geographic diversifications. In this paper, we substantiate the fact that these gains exist. We also substantiate that portfolio risk reduction is greatest when strategies based on meanvariance efficiency are followed. Mortgage portfolio investors, such as 


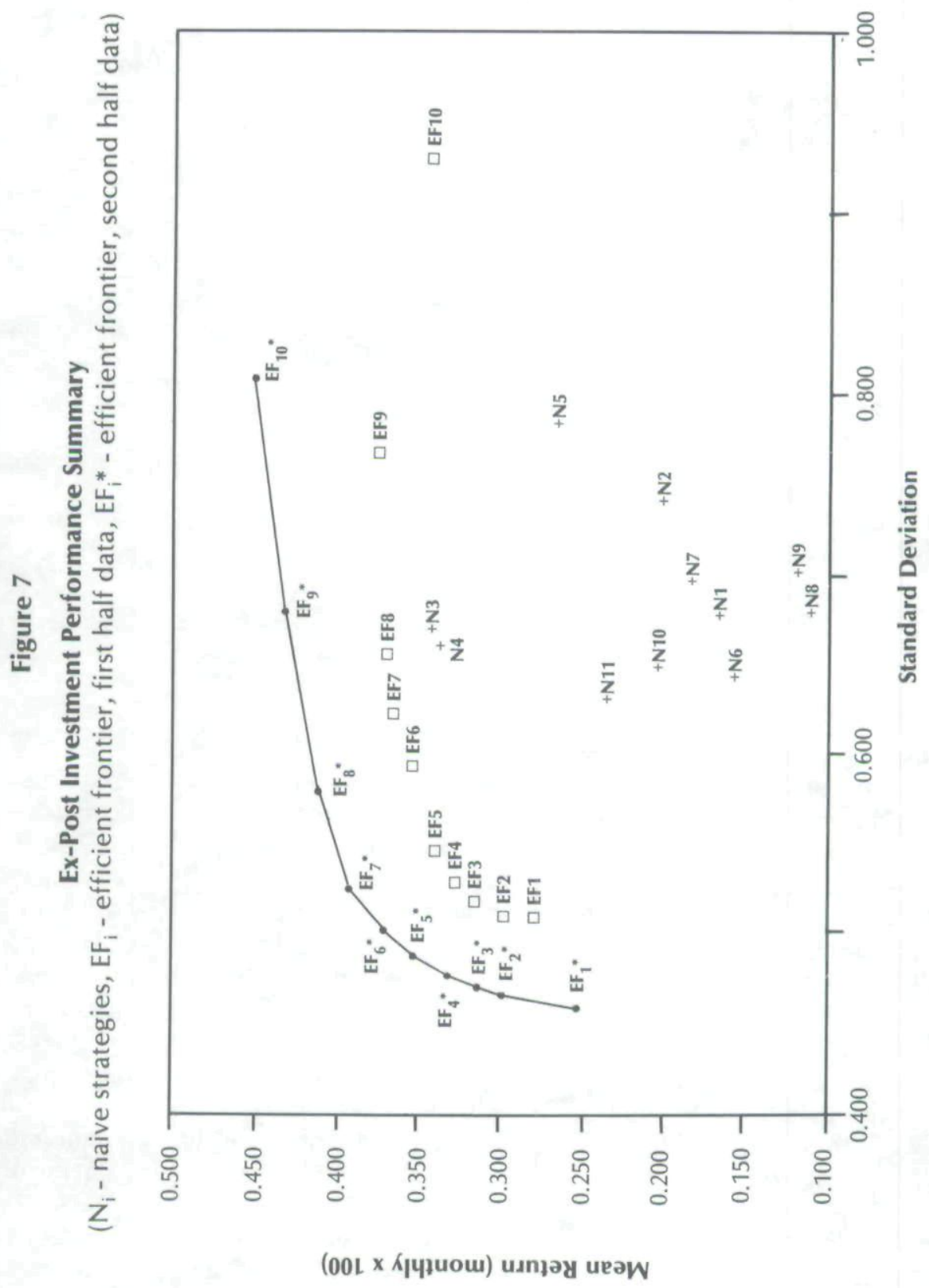


mortgage lenders, insurers, and secondary mortgage participants who follow naive diversification strategies(e.g., investing only in sunbelt or large metropolitan areas) are not likely to achieve optimal risk return relationships.

Research support was provided by the Homer Hoyt Institute, a non-profit foundation that promotes research in real estate and land economics, and by the College of Business Administration, Georgia State University. We are grateful for the research assistance of Seokchin Kim and Changi Nam.

\section{REFERENCES}

[1] T.S. Campbell and J.K. Dietrich. The Determinants of Default on Insured Conventional Residential Mortgage Loans. Journal of Finance 38(5): 1569-1581, December 1983.

[2] D.F. Cunningham and P.H. Hendershott. Pricing FHA Mortgage Default Insurance. Housing Finance Review 3(4):373-392, October 1984.

[3] K.B. Dunn and J.J. McConnell. A Comparison of Alternative Models for Pricing GNMA Mortgage-Backed Securities. Journal of Finance 36: 471-483, 1981.

[4] - Valuation of GNMA Mortgage-Backed Securities. Journal of Finance 36: 599-616, 1981.

[5] J.F. Epperson, J.B. Kau, D.C. Keenan and W.J. Muller III. Pricing Default Risk in Mortgages. AREUEA Journal 13(3): 261-272, Fall 1985.

[6] C. Foster and R. Van Order. FHA Terminations: A Prelude to Rational Mortgage Pricing. AREUEA Journal 13 (3): 273-291, Fall 1985.

[7] J. Gibbs and W. Martin. Urbanization Technology and Division of Labor: International Patterns. American Sociological Review 27, 1962.

[8] J. Green and J.B. Shoven. The Effects of Interest Rates on Mortgage Prepayments. Journal of Money, Credit and Banking 18(1): 41-59, February 1986.

[9] A.R. Hall. Valuing the Mortgage Borrower's Prepayment Option. AREUEA Journal 13(3): 229-247, Fall 1985.

[10] R. Hammond and P. McCullagh. Quantitative Techniques in Geography. Clarendon Press, 1978.

[11] B.F. King. Market and Industry Factors in Stock Price Behavior. Journal of Business 39 (1): 139-190, January (supplement) 1966.

[12] D.R. Lessard. International Portfolio Diversification: A Multivariate Analysis for a Group of Latin American Counties. Journal of Finance 28 (3): 619-634, June 1973.

[13] K. Mardia, J. Kent, and M. Bibby. Multivariate Analysis. Academic Press, 1979.

[14] H.F. Peters, S.M. Pinkus and D.J. Askin. Figuring the Odds: A Model of Prepayments. Secondary Mortgage Markets 1: 18-23, May 1984.

[15] R.L. Sandor and H.B. Sosin. The Determinants of Mortgage Risk Premiums: A Case Study of the Portfolio of a Savings and Loan Association. Journal of Business 48 (1): 27-38, January 1975.

[16] U.S. Department of Labor. Employment and Earnings. Bureau of Labor Statistics, 1969 through 1984.

[17] K.D. Vandell. Default Risk Under Alternative Mortgage Instruments. Journal of Finance 33 (5): 1279-1296, December 1978.

[18] K.D. Vandell and T. Thibodeau. Estimation of Mortgage Defaults Using Disaggregate Loan History Data. AREUEA Journal 13 (3): 292-316, Fall 1985. 